\title{
Nota Farmacológica: Varenicline: un nuevo tratamiento farmacológico para dejar de fumar
}

\author{
Varenicline: a new pharmacologic treatment for smoking cessation.
}

Karina Bakalar* y Verónica Schoj**

\begin{abstract}
Resumen
Comparado con placebo, varenicline se asoció a casi tres veces la probabilidad de éxito en la cesación tabáquica en el largo plazo, y fue más efectivo que bupropion con un efecto discreto en el largo plazo que requiere mayor investigación. Sería importante contar con comparaciones de varenicline contra sustitutos nicotínicos y con estudios de costoefectividad, para la toma de decisiones clínicas y poblacionales en nuestra región.

\section{Abstract}

When it was compared with placebo, varenicline was associated almost three times the probability of success of long time smoking cessation; and was more effective than bupropion with a little long term effect that requires more investigation. Investigation comparing varenicline and nicotine substitutes, and cost-effectiveness evaluation should be important for individual and social decision-making in our region.
\end{abstract}

Palabras clave: varenicline, bupropion, cesación tabáquica. Key words: Varenicline, bupropion, smoking cessation.

Bakalar K, Schoj V. Varenicline: un nuevo tratamiento farmacológico para dejar de fumar. Evid. actual. práct. ambul; 10(2):55-57, mar-abr.2007.

\section{Introducción}

El tabaquismo es la principal causa evitable de morbimortalidad prematura en todo el mundo. La mayoría de los fumadores quiere dejar de fumar, sin embargo dejar de fumar es muy difícil y la recaída constituye en una parte normal del proceso de recuperación. Los fumadores suelen realizar varios intentos de cesación y es común que recaigan varias veces antes de lograr dejar de fumar definitivamente. Por lo tanto, la aparición de un nuevo recurso terapéutico para el tratamiento de esta adicción y su gran difusión a través de los medios de comunicación, genera importantes expectativas en los fumadores, lo que puede ser interpretado como una solución mágica o panacea. Los médicos debemos estar suficientemente informados para transmitir el verdadero aporte de este nuevo recurso en el tratamiento del tabaquismo y así garantizar su uso clínico apropiado'.

\section{Mecanismo neuroquímico de la adicción al tabaco}

Los receptores de acetilcolina del sistema nervioso son estructuras proteicas que se activan con la presencia de su neurotransmisor o ligando endógeno. Existen dos tipos de receptores de acetilcolina, los que se unen a la nicotina (RNE) y los que lo hacen a la muscarina, ambos ligandos exógenos. Hay actualmente 16 variedades de RNE, según la combinación de subunidades que los integran. La sub-unidad a4B2, y a7 serían las responsables de los fenómenos de la adicción.

La nicotina actúa sobre el Área Tegmental Ventral del mesencéfalo y despolariza el RNE al ligarse con la subunidad alfa, entonces, la subunidad beta, estimula la liberación de dopamina en el núcleo accumbens, generando así una sensación de placer o "recompensa" que promueve y sostiene la adicción².

\section{Cyticine: precursor de Varenicline}

Durante la segunda guerra mundial, la hoja del Cytisus laburnum o "árbol de lluvia dorada" fue una planta alcaloide utilizada por los fumadores como sustituto del tabaco. En 1955, una publicación sobre el C. laburnum, que contiene cystisine, valoró esta sustancia como tratamiento para la dependencia del tabaco; y en 1978, la industria identificó al cytisine como una sus- tancia con acción farmacológica muy similar a la nicotina. Al igual que la nicotina, el cytisine es un insecticida natural. Ha sido usado por décadas para la cesación tabáquica en países de Europa del Este desde hace más de 40 años, hecho que no había sido notificado probablemente, por que no había información publicada en revistas científicas de lengua inglesa. Su toxicidad no ha sido aún bien definida ${ }^{3}$.

Tiene una estructura molecular similar a la nicotina y a la acetilcolina y es un agonista del receptor nicotínico de acetilcolina.

\section{Varenicline y su mecanismo de acción}

El varenicline fue desarrollado en 1997 a partir del cytisine y es un agonista parcial del receptor nicotínico de la acetilcolina'. Tiene como mecanismo de acción la activación selectiva los receptores $\mathrm{a} 4 \mathrm{~b} 2$, generando por el efecto de agonista, un aumento de dopamina, que a su vez produce una disminución del deseo imperioso de fumar y del síndrome de abstinencia; $y$ por otro lado, actúa como antagonista, bloqueando los receptores y disminuyendo así el efecto de la recompensa (o alivio) que experimenta el fumador al fumar, durante el periodo de abstinencia ${ }^{4,5}$.

En el último año se publicaron varios ensayos clínicos con varenicline que en enero del 2007 fueron analizados en un meta-análisis de la Colaboración Cochrane'.

\section{Resumen de los resultados del Meta-análisis de Cochrane sobre Varenicline y cytisine}

El objetivo de la revisión fue valorar la eficacia y la tolerabilidad del varenicline y del cytisine para la cesación tabáquica. Se incluyeron ensayos clínicos que compararon la droga varenicline o cytisine contra placebo o contra bupropion (cuando estuvo disponible). El principal resultado medido fue la abstinencia continua, es decir aquella en que el participante no hubiera dado ni siquiera una pitada desde la fecha de cesación y se reportaron las tasas de abstinencia con validación bioquímica siempre que estuvieron disponibles. Fueron seleccionados solamente los estudios con un tiempo mínimo de seguimiento de seis meses luego de la cesación. Fueron incluidos ensayos clínicos: cinco compararon varenicline contra placebo $4,5,6,7,8$ (tres de ellos también incluyeron la rama bupropion $^{4,5,7}$ ) uno fue de prevención de recaída y que comparó varenicline con placebo $^{9}$ y por último, otro comparó cytisine contra placebo ${ }^{3}$.

* Médica Especialista en Medicina Familiar. Servicio de Medicina Familiar y Comunitaria y Grupo Anti tabaco del Hospital Italiano de Buenos Aires. ** Médica Especialista en Medicina Familiar. Servicio de Medicina Familiar y Comunitaria y Grupo Anti tabaco del Hospital Italiano de Buenos Aires. 
La abstinencia continua a los 12 meses fue significativamente mayor para los pacientes tratados con varenicline (OR 3,22 IC95\% 2,43-4,27) que para los que recibieron placebo y para los que recibieron bupropion (OR 1,66 IC95\% 1,28-2,16).

El principal efecto adverso del varenicline fueron las náuseas, mayormente de intensidad leve a moderada y que fueron cediendo con el correr del tiempo, otros fueron el insomnio, la cefalea y los sueños anormales ${ }^{1}$

El ensayo de cytisine encontró que a los dos años de seguimiento dejaron de fumar más participantes del grupo cytisine que del grupo placebo (OR 1,77 IC95\% 1,30-2,40)'.

Al la luz de la evidencia actual, las principales conclusiones de los autores del meta-análisis son que el varenicline es el triple de efectivo que el placebo y que es superior al bupropion, pero que se necesitan estudios independientes de la industria farmacéutica (dado que todos los ensayos clínicos habían sido financiados y manejados por Pfizer, el espónsor del varenicline). También concluyen que es necesario realizar estudios de varenicline contra sustitutos nicotínicos y mas estudios contra bupropion para determinar con mayor certeza la efectividad comparada.

\section{Indicación del Vareniclinice y modo de utilización}

Al igual que cualquier fármaco para dejar de fumar, debe indicarse en fumadores que hayan decidido hacer un intento de cesación y que estén dispuestos a poner una fecha precisa para dejar de fumar dentro del próximo mes.

Se administra por vía oral. La dosis recomendada es de $1 \mathrm{mg}$ dos veces al día, luego de una titulación progresiva de la droga durante los primeros siete días, llegando a la dosis deseada a octavo día (el cual coincidirá con el primer día de abstinencia o "libre de humo" o día "D"). La principal razón de dicha titulación es lograr la mejor tolerancia posible y menor incidencia de náuseas, su principal evento adverso. Ver cuadro 1.

Cuadro 1: dosificación recomendada de varenicline para dejar de fumar.

- Primer día al tercero: 0,5mg, una vez al día.

- Cuarto día al séptimo: $0,5 \mathrm{mg}$, dos veces al día.

- Desde el día elegido para dejar de fumar hasta completar 12 semanas de tratamiento: $1 \mathrm{mg}$, dos veces al día (mañana y noche).

El tratamiento debe iniciarse una o dos semanas antes del día "D". En aquellos pacientes que no puedan tolerar los efectos adversos de varenicline, deberá reducirse la dosis de forma temporal o permanente a $0,5 \mathrm{mg}$ dos veces al día. Los comprimidos de varenicline deben tragarse enteros con agua y pueden ingerirse con y sin alimentos. Los pacientes deben ser tratados con varenicline durante 12 semanas.

Como puede producir mareos y somnolencia, puede afectar la capacidad para conducir y utilizar maquinaria.

\section{Presentación}

Hay dos presentaciones en Argentina: Champixâ kit de inicio y Champixâ x 28 comprimidos.

Champix kit de inicio: un cronograma (día a día) para facilitar la titulación de la dosis del fármaco durante la primera semana (similar a como vienen las cajas de anticonceptivos con el número de días impreso en el "blister").

Para los tres primeros días trae un solo comprimido de $0,5 \mathrm{mg}$; para los cuatro días siguientes, dos comprimidos de $0,5 \mathrm{mg}$ (mañana y noche); y luego la dosis de mantenimiento durante tres meses: comprimidos de $1 \mathrm{mg}$ para tomar uno por la mañana y otro por la noche.

Champixâ x 28 comprimidos (por 28 comprimidos): trae 28 comprimidos de $1 \mathrm{mg}$ cada uno.

Se debe indicar una sola caja del kit de inicio y luego todas las restantes cajas comunes de 28 comprimidos de $1 \mathrm{mg}$.

\section{Comentario}

El varenicline es un recurso farmacológico eficaz para la cesación tabáquica, que aumenta la oferta de tratamientos disponibles para la práctica clínica. No obstante creemos que deben realizarse algunas consideraciones en relación a su superioridad respecto al bupropion.

Si bien el varenicline fue superior al bupropion en el corto y en el largo plazo (según se muestra en el resultado combinado del meta-análisis) la diferencia a favor del varenicline fue muy importante al final del tratamiento (a las 12 semanas) pero fue contundentemente menor al año (a pesar de conservar significancia estadística). Ciertos hallazgos en los ensayos clínicos que compararon ambas drogas abren interrogantes sobre potenciales sesgos. Por ejemplo, en los estudios de Joremby ${ }^{5}$ y de Nides $^{7}$ (ambos publicados durante 2006) no hubo diferencia estadísticamente significativa entre las ramas bupropion y placebo respecto de la abstinencia continua al año. Incluso, en el estudio de $\mathrm{Nides}^{7}$ sólo hubo diferencia entre el bupropion y el placebo hasta las 12 semanas, lapso luego del cual los pacientes asignados a ambos tratamientos tuvieron similares resultados.

Estos hallazgos sorprenden a la luz de la evidencia de un metaanálisis de Cochrane 2007 que incluye 31 ensayos clínicos de bupropion contra placebo y que reporta una abstinencia continua de franca superioridad a favor del bupropion (OR: 1,94; IC95: 1,72-2,19) con un mínimo de seguimiento de seis meses o más ${ }^{11}$.

Si se lo compara con los recursos disponibles hasta hoy (bupropion y sustitutos de la nicotina) con mejor perfil de efectos adversos, el varenicline presentó una alta tasa de náuseas (alrededor de $30 \%$ ) lo que podría generar en la práctica clínica potenciales dificultades en la adherencia. Además, los pacientes que recibieron varenicline subieron más de peso que lo que usaron bupropion, otro de los temas de relevancia en la agenda clínica de la cesación tabáquica.

El alto costo del varenicline en Argentina $(\$ 1128$ el tratamiento completo) representa otro tema a considerar, dado que es el triple de lo que cuestan los parches y más del cuádruple de lo que cuesta el bupropion. Este no es un tema menor, particularmente en un país de alta prevalencia de consumo, con la mitad de la población bajo la línea de pobreza y que aún no ha resuelto la cobertura de los tratamientos farmacológicos para dejar de fumar.

En último lugar, será muy útil, contar con resultados de estudios de costo-efectividad para guiar el proceso de toma de decisiones clínicas en la práctica cotidiana y contar con estudios independientes no financiados por el espónsor de la droga, como sugieren los autores del Meta-analisis de Cochrane.

El tabaquismo no puede tratarse sólo desde el punto de vista farmacológico, es una adicción muy compleja y poderosa que requiere un abordaje psicosocial brindado por el equipo de salud -al menos una intervención breve- en el contexto de un 
paciente motivado para dejar de fumar.

Algunas de las preguntas pendiente son: ¿cuáles serán los criterios para seleccionar los pacientes que debieran recibir varenicline? ¿se convertirá varenicline en una droga de primera elección?
Estas preguntas aún no están respondidas en la bibliografía y pareciera razonable esperar a contar con mas datos de efectividad comparada contra bupropion y contra sustitutos nicotínicos, así como datos de costo-efectividad para que las próximas guías de práctica clínica las respondan.

Recibido el 24/04/07 y aceptado el 26/04/07

\section{Referencias}

1. K. Cahill, LF Stead, T Lancaster. Nicotine receptor partial agonists for smoking cessation. Cochrane Database of Systematic Reviews 2007, Issue 1. Art.No: CD006103.DOI:10.1002/14651858.

2. B. A. Johnson. New Weapon to Curb Smoking. Arch Intern Med. 2006; 166:1547-1550.

3. J. F Etter. Cytisine for Smoking Cessation. Arch Intern Med. 2006;166:1553-1559.

4. D. Gonzales, S.I. Rennard, M. Nides, C. Oncken, S. Azoulay, C. B. Billing, E. J. Watsky, J. Gong, K. E Williams, K. R. Reeves. Varenicline, an a4b2 Nicotinic Acetylcholine Receptor Partial Agonist, vs Sustained-Release Bupropion and Placebo for Smoking Cessation. JAMA. 2006;296:47-55.

5. D. E. Jorenby, J. Taylor Hays, N. A. Rigotti, S. Azoulay, E. J. Watsky, K. E. Williams, C. B. Billing, J. Gong, K.R reeves. Efficacy of Varenicline, an 42 Nicotinic Acetylcholine Receptor Partial Agonist,vs Placebo or Sustained-Release Bupropion for Smoking Cessation. JAMA. 2006;296:56-63.

6. S. Tonstad, P. Tonnesen, P. Hajek, K. E. Williams, C. B. Billing, K. R. Reeves. Effect of Maintenance Therapy With Varenicline on Smoking Cessation. JAMA. 2006;296:64-71. 7. M. Nides, Ch. Oncken, D. Gonzales, S. Rennard, E. J. Watsky, R. Anziano, K. Reeves. Smoking Cessation With Varenicline, a Selective a4b2 Nicotinic Receptor Partial Agonist. Arch Intern Med. 2006;166:1561-1568.

8. Ch. Oncken, D Gonzales, M. Nides, S. Rennard, E.J. Watsky, C.B. Billing, R. Anziano, K. Reeves. Efficacy and Safety of the Novel SelectiveNicotinic Acetylcholine Receptor Partial Agonist,Varenicline, for Smoking Cessation. Arch Intern Med. 2006;166:1571-1577.

9. Reeves K, Watsky E, Williams K, Azoulay S, Billing B, Gong J. The safety of varenicline taken for 52 weeks for smoking cessation [RPOS3-54]. Society for Research on Nicotine and Tobacco 12th Annual Conference Orlando Fla, USA 2006.

10. R.C. Klesges, K.C Johnson, G. Somes. Varenicline for Smoking Cessation. JAMA. 2006;296: 94-95.4.

11. Hughes JR, Stead LF, Lancaster T Antidepressants for smoking cessation (Review) Cochrane Library 2007
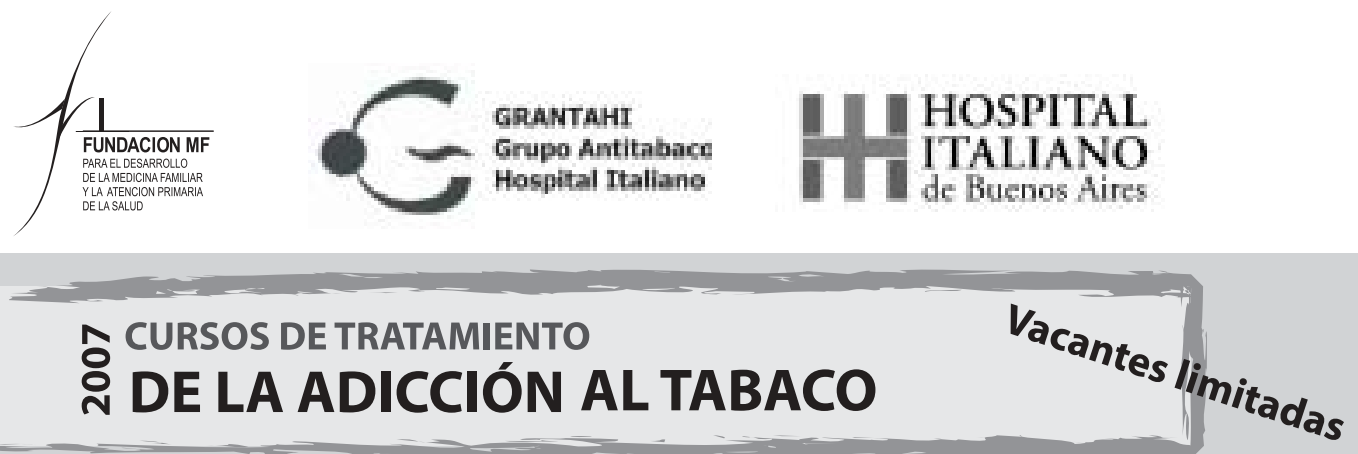

- Dirigido a todo el equipo de salud: médicos, enfermeros,psicólogos y demás profesionales que ejercen su práctica en el ámbito de la salud.

- Tiene por objetivos: capacitar a los profesionales en intervenciones prácticas y basadas en la evidencia, para ayudar a los pacientes a dejar de fumar en el consultorio y brindar una herramienta para que cada cual pueda incorporar los últimos tratamientos de la adicción al tabaco en su práctica cotidiana.

El curso se realiza durante dos días, viernes y sábado, 12 hs de cursada.

Fechas que se desarrollarán los cursos (dos días de cursada en total para cada curso)

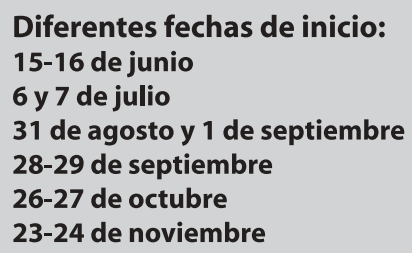

Para mayor información contáctese con:

Fundación MF

Sra Claudia Barberón

Tel:(011) 4959-0381 de lunes a viernes de 9 a 18 hs. 